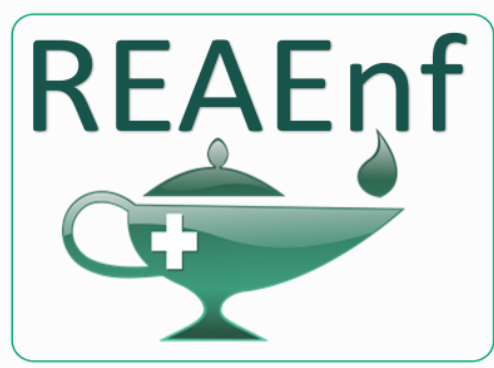

Revista Eletrônica Acervo Enfermagem

\section{REVISÃO LITERATURA}

Recebido em: 10/2019

Aceito em: 10/2019

Publicado em: 10/2019

\title{
Atuação da enfermagem no atendimento as urgências e emergências de pacientes vítimas de queimadura: uma análise conceitual
}

\author{
Nursing action in care of urgences and emergencies of patients burning victims: a \\ conceptual analysis
}

\section{Acción de enfermería en cuidado de urgencias y emergencias de pacientes que victimas encendidas: un análisis conceptual}

Diony Kelly Lima do nascimento ${ }^{1}$, Anderson Campos Barros ${ }^{2 \star}$, Henry Walber Dantas Vieira ${ }^{3}$.

\begin{abstract}
Resumo: O presente estudo permitiu avaliar a ação da equipe de enfermagem em feridas provocadas por queimaduras. Trata-se de uma análise conceitual exploratória de artigos científicos recuperados das seguintes bases de dados: Biblioteca Eletrônica Científica Online (SCIELO) e Literatura Latino-americana e do Caribe em Ciências da Saúde (Lilacs). Com finalidade de descrever a assistência prestada pela equipe de enfermagem no atendimento as urgências e emergências de pacientes vítimas de queimadura. Nesta análise foi possível identificar as características de feridas traumáticas provocadas por queimaduras, que consiste em um amplo problema de saúde pública, provocando um impacto direto nas condições econômicas e sociais. Foi identificado que a equipe de enfermagem tem um papel importante na assistência aos pacientes vítimas desse tipo de trauma, pois, estes profissionais atuam diretamente no atendimento inicial, caracterizando por casos de urgência ou emergência, até a total ou parcial recuperação da área afetada, diminuindo os riscos provenientes, geralmente, do agente causador da queimadura.
\end{abstract}

Palavras-chave: Enfermagem, Queimadura, Cuidados de Enfermagem.

\begin{abstract}
The present study allowed to evaluate the action of the nursing team in burn wounds. This is an exploratory conceptual analysis of scientific articles retrieved from the following databases: Scientific Electronic Library Online (SCIELO) and Latin American and Caribbean Health Sciences Literature (Lilacs). In order to describe the care provided by the nursing staff in the care of emergency patients burn victims. In this analysis it was possible to identify the characteristics of traumatic wounds caused by burns, which is a broad public health problem, causing a direct impact on economic and social conditions. It was identified that the nursing team has an important role in assisting patients who are victims of this type of trauma, as these professionals act directly in the initial care, characterized by urgent or emergency cases, until the total or partial recovery of the affected area, reducing the risks usually arising from the causative agent of the burn.
\end{abstract}

Keywords: Nursing, Burn, Nursing care.

\footnotetext{
${ }^{1}$ Enfermeira. Especialista em Urgência e Emergência pelo Centro de Formação, Pós-graduação e Pesquisa em Saúde (CEFAPP/AM), Manaus/AM.

2 Enfermeiro. Especialista em Urgência e Emergência e Unidade de Terapia Intensiva Adulto pelo Instituto Singular/AM, Manaus/AM. *E-mail: andersonnn.campos@gmail.com.

3 Enfermeiro. Doutor em Ciências pela Escola de Enfermagem da Universidade de São Paulo (EE-USP). Professor da Escola de Enfermagem de Manaus da Universidade Federal do Amazonas (EEM/UFAM), Manaus/AM.
} 
Resumen: El presente estudio permitió evaluar la acción del equipo de enfermería en las quemaduras. Este es un análisis conceptual exploratorio de artículos científicos recuperados de las siguientes bases de datos: Biblioteca electrónica científica en línea (SCIELO) y Literatura latinoamericana y caribeña de ciencias de la salud (Lilacs). Con el fin de describir la atención brindada por el personal de enfermería en la atención de pacientes de emergencia queman víctimas. En este análisis fue posible identificar las características de las heridas traumáticas causadas por quemaduras, que es un amplio problema de salud pública, que tiene un impacto directo en las condiciones económicas y sociales. Se identificó que el equipo de enfermería tiene un papel importante en ayudar a los pacientes que son víctimas de este tipo de trauma, ya que estos profesionales actúan directamente en la atención inicial, caracterizada por casos urgentes o de emergencia, hasta la recuperación total o parcial del área afectada, reduciendo Los riesgos generalmente surgen del agente causante de la quemadura.

Palabras clave: Enfermería, Quemadura, Cuidados de enfermería.

\section{INTRODUÇÃO}

As queimaduras são caracterizadas como feridas traumáticas, oriundas, frequentemente, por intermédio de agentes térmicos, químicos, elétricos ou radioativos. Caracterizando-se por destruição segmentada ou completa do tecido tegumentar e seus contíguos, sendo capaz de alcançar a epiderme, derme, hipoderme ou tecido subcutâneo, músculos e tendões (SILVA LD, et al., 2018).

Apontada como um trauma grave de alta complexidade e dificultoso tratamento, consiste em um amplo problema de saúde pública, provocando um impacto direto nas condições econômicas e sociais (QUEIROZ RCPF, et al., 2015).

No que tange a gravidade e classificação das queimaduras, baseiam-se de numerosos fatores conforme a temperatura do agente térmico, período de exposição ao causador do trauma, categoria do agente e seu calor característico, da mesma maneira que o mecanismo de lesão, grau, profundidade, área corporal afetada, região ou delimitação de parte do corpo acometido e sua extensão (QUEIROZ RCPF, et al., 2015).

$\mathrm{Na}$ finalidade de classificação e o melhor diagnóstico de um paciente queimado, é fundamental que se considere a extensão e a profundidade da lesão. Estes fatores podem guiar as condutas clínicas e cirúrgicas na região afetada pelo trauma (SILVA JB, et al., 2015).

As queimaduras são classificadas em graus de profundidade: Grau primeiro, acometimento epiderme, com características Eritematosa, dolorida, seca; Grau Segundo (superficial), acometimento Epiderme e derme (até camada papilar), com características Rosada, bolhas, enchimento capilar; Grau Segundo (profunda), acometimento Epiderme e derme (até camada reticular), destrói terminações nervosas, com características: Pálido; Grau Terceiro, acometimento de todas as camadas da epiderme e derme, e possível subcutânea, com características como, pálida a fracamente escurecida, indolor, necrose total ou escara necrótica, sem bolhas (SILVA JB, et al., 2015).

Já a classificação quanto à extensão e gravidade da queimadura, avalia-se pelo método de LundBrowder: $2^{\circ}$ grau, comprometimento Leve $<15 \%$, Moderada $15 \%$ a $25 \%$, Grave $>25 \%$; $3^{\circ}$ grau, comprometimento Leve $<2 \%$, Moderada 3\% a 10\%, Grave $>10 \%$ (SILVA JB, et al., 2015).

Em relação a extensão da superfície corpórea lesionada, as queimaduras podem ser calculadas em porcentagem da área queimada (ATSQ - Área Total da Superfície corporal Queimada). Além disso, alguns autores, em relação a profundidade, não se limitam em classificar apenas em $1^{\circ}, 2^{\circ}$ ou $3^{\circ}$ grau, estes, classificam as queimaduras em até $4^{\circ} \mathrm{grau}$. Dessa forma, categorizam-se como queimaduras possíveis de ultrapassar o tecido tegumentar e alcançar, músculos, ossos ou até órgãos profundos, sendo esta a de maior gravidade (JÚNIOR JLR, et al., 2014).

Embora não haja um estudo epidemiológico no âmbito mundial preciso, a Associação Americana de Queimaduras estabeleceu um levantamento de dados numa escala semelhante, no ano de 2012, apurado

REAEnf/EJNC | Vol. 1 | e2122 | DOI: https://doi.org/10.25248/REAenf.e2122.2019 Página 2 de 9 
nos EUA, Canadá e Suécia, concluindo que, de 183.000 pacientes atendidos no período de 2002 a 2011 em 91 hospitais especializados no tratamento de queimaduras, $12 \%$ dos casos correspondiam a pessoas com mais de 60 anos (SILVA RV, et al., 2015).

No Brasil, de acordo com a Sociedade Brasileira de Queimaduras, ocorrem 1 milhão de casos de queimaduras anualmente, sendo que 200 mil são encaminhados para atendimentos em serviços de emergência e 40 mil necessitam de serviços de hospitalização especializados. Sendo consideradas as principais causas externas de morte registradas no país, as queimaduras perdem em números somente para outras causas violentas, que incluem acidentes de transporte e homicídios (GONELLA HÁ, et al., 2014).

A queimadura é tida como um trauma grave, de repercussões sociais na saúde pública brasileira e na economia, no qual somente $37 \%$ dos pacientes voltam ao trabalho, e tal porcentagem possui relação direta com ATSQ. Entretanto, pode-se afirmar que este tipo de trauma está entre as principais causas de morbidade e mortalidade, atingindo com maior frequência crianças menores de 5 anos e adultos acima de 65 anos (BISCEGLI TS, et al., 2014).

As crianças são um grupo etário de maior incidência. Como os principais responsáveis de queimaduras nesta faixa etária apontam-se as ocorrências acidentais em ambiente doméstico, correspondendo os traumas por líquidos aquecidos e a manipulação de produtos químicos ou inflamáveis as principais causas (LIMA GM, et al., 2015).

O agente causador varia de acordo com a idade, no caso dos menores de dois anos, prevalecem os banhos em água excessivamente quente. Em relação aos pré-escolares, dos dois aos sete anos, as substâncias inflamáveis apresentam maior prevalência. Já em escolares e adolescentes, há a predominância da queimadura por combustão. Contudo, independentemente da idade, ocorrem frequentes acidentes ocasionados por adultos, ainda que não haja a intenção (LIMA GM, et al., 2015).

O tratamento das queimaduras possui um alto grau de dificuldade, não obstante a gravidade das lesões, há também as inúmeras complicações provenientes dos tipos de agente causador e a vulnerabilidade às infecções. À medida que, se não provocam à morte, podem gerar consideráveis limitações funcionais, psicológicas e sociais. Além das complicações no decorrer da internação que podem implicar em sequelas por toda a vida (MORAES PS, et al., 2014).

No que tange aos cuidados de enfermagem nessa área, há poucas prioridades e definições, devido a falta de estímulo dos profissionais, poucos programas de capacitação, além da falta de uma política de recursos humanos que atue na quantidade de profissionais e na capacitação continuada (PINHO FM, et al., 2016).

Entretanto, nos pacientes queimados, observa-se, durante a internação, um risco elevado de desenvolver infecções e sepse, considerados a maior causa de morte em pacientes queimados que suportam o choque inicial. Por isso, esse risco deve ser combatido pela equipe multidisciplinar de saúde (SILVA JAC, et al., 2018).

Diante disto, a eficiência no tratamento agudo de indivíduos queimados está relacionada a quantidade de pessoas que sobrevivem a esses acidentes, maiores índices de sequelas e cirurgias reparadoras. Os serviços especializados em atendimento à pessoa queimada exercem um papel direto no processo de reintegração social. As manifestações físicas, psicológicas e psicossociais influenciam a qualidade de vida destes pacientes, além dos, ao longo do tempo, problemas emocionais e a gravidade da queimadura (ECHEVARRÍA GME, et al., 2016).

De uma maneira geral, no trauma por queimadura, analisa-se inicialmente a segurança da cena e da equipe e extinção da fonte de origem. Posteriormente, avalia-se a etapa primária e secundária. $\mathrm{Na}$ avaliação primária, nos casos de queimadura, ocorre de maneira semelhante as de trauma, seguindo o $A B C D E$, no qual o elemento $A$ representa a via aérea com controle de cervical; $B$, respiração e ventilação; $C$, circulação e controle de hemorragia; $D$, avaliação neurológica e $E$, exposição/ambiente. Em relação a

REAEnf/EJNC | Vol. 1 | e2122 | DOI: https://doi.org/10.25248/REAenf.e2122.2019 Página 3 de 9 
avaliação secundária engloba a classificação da extensão da área queimada, curativos e transporte (MOULIN LL, et al., 2018).

Desta forma, ao oferecer assistência ao paciente queimado, a equipe de enfermagem enfrenta uma rotina de intenso trabalho, de dor e sofrimento, de depressão, de padrão de sono perturbado, de mobilidade prejudicada, de imprecisões sobre às sequelas das queimaduras, e demais fatores, que podem atingir os seus familiares. Com isso, esse tipo de assistência é considerado desgastante e pode causar mudanças na saúde dos profissionais da área de saúde, responsáveis pelo cuidado direto ao indivíduo (MARTINS JT, et al., 2014).

Entretanto, o avanço tecnológico vem proporcionando melhores possibilidades terapêuticas diante da complexidade assistencial aos paciente queimado. Nesse contexto, destaca-se a atuação dos profissionais de enfermagem, que deve ser segura e de qualidade, considerando a integração entre as ações gerenciais e assistenciais do enfermeiro, que deve ser capacitado e atualizado para a melhor tomada de decisão quanto ao atendimento do paciente queimado (MELO TO e LIMA AFC, 2017).

Assim, é relevante responder à pergunta da pesquisa: Qual a assistência de enfermagem no atendimento as urgências e emergências de pacientes vítimas de queimadura.

\section{MÉTODOS}

Trata-se de uma análise conceitual exploratória por meio das bases de dados consultados: Biblioteca Eletrônica Científica Online (SCIELO) e Literatura Latino-americana e do Caribe em Ciências da Saúde (Lilacs).

A amostra contou com 43 artigos sobre o tema assistência ao paciente queimado no período de 2008 a 2018. Os critérios de inclusão foram: artigo científico, com resumo disponível on-line, publicados entre janeiro de 2013 a junho de 2018.

As variáveis primárias: País onde foi realizado o estudo; Idioma de Publicação; Desenho do estudo; Período do Estudo; População dos estudos. Para a seleção dos estudos foram obedecidas as seguintes etapas: Avaliação do título, avaliação do resumo e leitura do artigo completo.

E com o intuito de análise, a partir desta busca será elaborada uma tabela com caracterização e descrição dos estudos pertinentes do problema de pesquisa.

Os descritores foram: "Queimadura" or "Cuidados de enfermagem" or "Enfermagem". Os critérios de exclusão foram: ano de publicação, títulos não condizentes com o objeto de estudo, resumos que fogem o tema principal.

\section{RESULTADOS e DISCUSSÃO}

De maneira geral, os autores concordam que a queimadura é um trauma grave, de tratamento complexo e multiprofissional, que pode gerar sequelas funcionais, estéticas, psicológicas e até mesmo a morte. Resultam, também, repercussões sociais, econômicas e de saúde pública. Pesquisas realizadas nas bases de dados científicos revelam proporcional carência de estudos epidemiológicos direcionados ao tema em nosso país, centralizados em alguns poucos centros especializados no tratamento desse tipo de trauma e em dados internacionais (PADUA GAC, et al., 2017).

$\mathrm{Na}$ base de dados do LILACS foram recuperadas 343 referências, na avaliação de títulos foram excluídos 283 artigos pelo seguinte motivo: títulos não condizentes com o objeto de estudo. Após avaliação foram analisados 60 resumos.

$\mathrm{Na}$ avaliação dos resumos, 20 foram selecionados para análise de texto completo dos quais 14 foram incluídos para análise final (Figura 1). 
Figura 1 - Organograma representando os critérios de inclusão e exclusão na base de dados LILACS

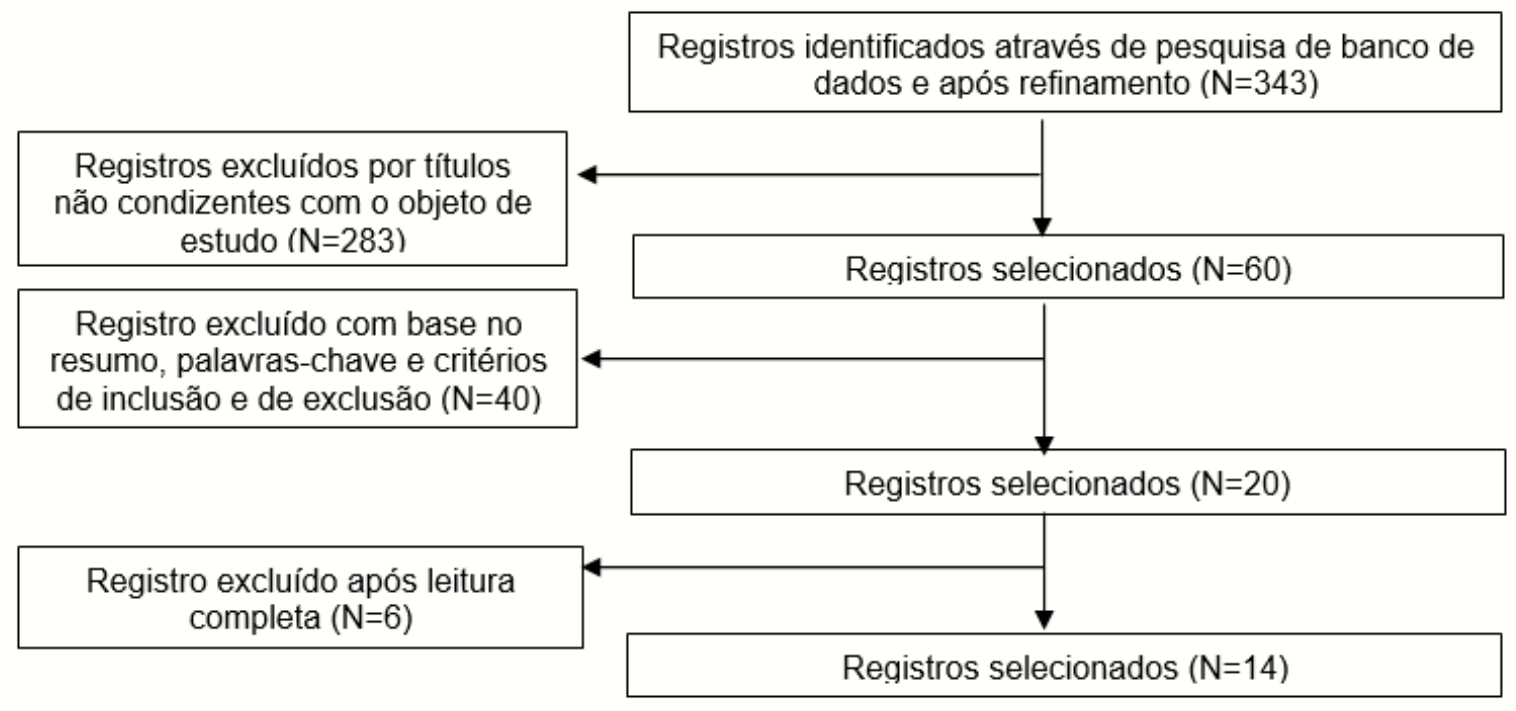

Fonte: Nascimento DKL, et al., 2018.

No SCIELO, foram recuperados 23 artigos, sendo que 10 foram excluídos na análise de títulos. Na análise de 13 resumo, 7 artigos foram excluídos. Sobraram 6 artigos para análise de texto completo dos quais 6 estudos foram incluídos para análise final (Figura 2).

Figura 2 - Organograma representando os critérios de inclusão e exclusão na base de dados SCIELO.

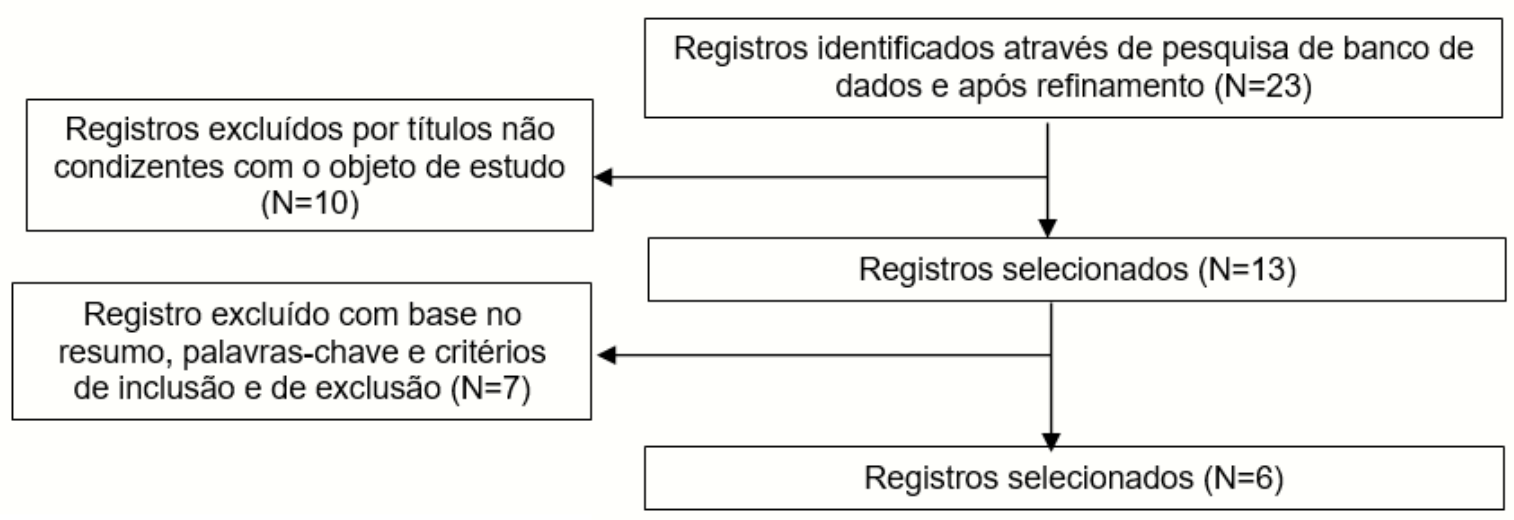

Fonte: Nascimento DKL, et al., 2018.

Em números consideráveis, estudos sobre pacientes vítimas de queimaduras afirmam a inevitabilidade da epidemiologia na prevenção deste tipo de trauma. Observa-se a importância da prevenção para diminuir a morbidade e a mortalidade geradas pelas queimaduras, de maneira que a maioria é evitável. Propostas sobre prevenção são a melhor forma de evitar as queimaduras e seus efeitos lesivos ao ser humano (PADUA GAC, et al., 2017).

$\mathrm{Na}$ análise de todos os artigos foram criados uma tabela, encontrada anexada, que possui informações relevantes para análise comparativa dos artigos referenciados, conforme, descrito na Tabela 1 que informa as características gerais dos artigos quanto aos autores, ano de publicação, país onde o estudo foi realizado, idioma de publicação, desenho e duração do estudo, amostra inicial e final, e população estudada. 
Tabela 1 - Apresenta a descrição do estudo sobre: Atuação da enfermagem no atendimento as urgências e emergências de pacientes vítimas de queimadura quanto aos autores, ano de publicação, país onde o estudo foi realizado, idioma de publicação, desenho e duração do estudo, amostra inicial e final, e população estudada.

\begin{tabular}{|c|c|c|c|c|c|}
\hline Autor-Ano & $\begin{array}{l}\text { País do estudo } \\
\text { realizado }\end{array}$ & $\begin{array}{l}\text { Idioma de } \\
\text { Publicação }\end{array}$ & Desenho do estudo & Período do Estudo & População dos estudos \\
\hline $\begin{array}{l}\text { Silva LD da, et } \\
\text { al (2018). }\end{array}$ & Brasil & Português & $\begin{array}{l}\text { Estudo } \\
\text { retrospectivo }\end{array}$ & Entre 2000 a 2011 & $\begin{array}{l}\text { Pacientes queimados em uso de analgésicos e } \\
\text { sedativos. }\end{array}$ \\
\hline $\begin{array}{lr}\text { Queiroz } & \text { RCPF } \\
\text { de, et al } & (2015) .\end{array}$ & Brasil & Português & $\begin{array}{l}\text { Estudo exploratório, } \\
\text { descritivo, } \\
\text { quantitativo }\end{array}$ & $\begin{array}{l}\text { Novembro de } 2013 \text { a } \\
\text { maio de } 2014 .\end{array}$ & $\begin{array}{l}\text { Pacientes evasores atendidos no ambulatório de } \\
\text { queimados do Conjunto Hospitalar de Sorocaba. }\end{array}$ \\
\hline $\begin{array}{l}\text { Silva JB, et al } \\
(2015) \text {. }\end{array}$ & Brasil & Português & $\begin{array}{l}\text { Estudo } \\
\text { retrospectivo }\end{array}$ & $\begin{array}{l}\text { Fevereiro e julho de } \\
2015 .\end{array}$ & $\begin{array}{l}\text { Pacientes em atendimento inicial às queimaduras de } \\
\text { mão. }\end{array}$ \\
\hline $\begin{array}{l}\text { Júnior JLR, et al } \\
\text { (2014). }\end{array}$ & Brasil & Português & Estudo retrospectivo & Entre 2008 a 2013. & Pacientes sob terapia ocupacional em queimados. \\
\hline $\begin{array}{l}\text { Silva RV, et al } \\
\text { (2015). }\end{array}$ & Brasil & Português & $\begin{array}{l}\text { Estudo } \\
\text { retrospectivo }\end{array}$ & $\begin{array}{l}\text { Janeiro de } 2000 \text { a } \\
\text { dezembro de } 2012 .\end{array}$ & $\begin{array}{l}\text { Pacientes idosos que apresentam fatores de risco e } \\
\text { os métodos de prevenção de queimadura }\end{array}$ \\
\hline $\begin{array}{l}\text { Gonella HÁ, et } \\
\text { al (2014). }\end{array}$ & Brasil & Português & $\begin{array}{l}\text { Estudo Longitudinal } \\
\text { Prospectivo }\end{array}$ & Não informado. & $\begin{array}{l}25 \text { Pacientes atendidos no Centro de Tratamento de } \\
\text { Queimados (CTQ) do Conjunto Hospitalar de } \\
\text { Sorocaba }\end{array}$ \\
\hline $\begin{array}{l}\text { Biscegli TS, et } \\
\text { al (2014). }\end{array}$ & Brasil & Português & $\begin{array}{l}\text { Estudo transversal, } \\
\text { retrospectivo }\end{array}$ & Entre 2002 a 2012. & $\begin{array}{l}\text { Crianças e adolescentes internados em Unidade de } \\
\text { Tratamento de Queimados do interior do estado de } \\
\text { São Paulo }\end{array}$ \\
\hline $\begin{array}{l}\text { Lima GM de, et } \\
\text { al (2015). }\end{array}$ & Brasil & Português & $\begin{array}{l}\text { Estudo } \quad \text { quantitativo, } \\
\text { observacional, retrospectivo } \\
\text { e descritivo }\end{array}$ & $\begin{array}{l}\text { Agosto de } 2010 \text { a } \\
\text { maio de } 2012 \text {. }\end{array}$ & $\begin{array}{l}\text { Pacientes que apresentaram queimaduras de face no } \\
\text { Centro de Tratamento de Queimados do Hospital } \\
\text { Metropolitano de Urgência e Emergência. }\end{array}$ \\
\hline $\begin{array}{l}\text { Moraes PS de, } \\
\text { et al (2014). }\end{array}$ & Brasil & $\begin{array}{l}\text { Inglês, } \\
\text { Português }\end{array}$ & 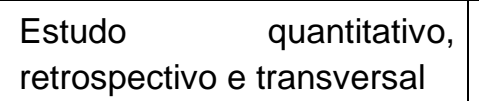 & Entre 2007 e 2011. & $\begin{array}{l}\text { Internações pediátricas de um Centro de Tratamento } \\
\text { para Queimados }\end{array}$ \\
\hline
\end{tabular}

REAEnf/EJNC | Vol. 1 | e2122 | DOI: https://doi.org/10.25248/REAenf.e2122.2019 Página 6 de 9 


\begin{tabular}{|c|c|c|c|c|c|}
\hline $\begin{array}{l}\text { Pinho FM de, et } \\
\text { al (2016) }\end{array}$ & Brasil & Português & $\begin{array}{ll}\text { Estudo } & \text { qualitativo } \\
\text { retrospectivo } & \end{array}$ & Maio a julho de 1999 & Pacientes adultos queimados \\
\hline $\begin{array}{l}\text { Silva JAC da, et } \\
\text { al (2018) }\end{array}$ & Brasil & $\begin{array}{l}\text { Inglês, } \\
\text { Português }\end{array}$ & Estudo retrospectivo & $\begin{array}{l}\text { Janeiro de } 2007 \text { até } \\
\text { dezembro de } 2012 .\end{array}$ & $\begin{array}{l}\text { Pacientes atendidos em um Centro de Tratamento de } \\
\text { Queimados na Amazônia }\end{array}$ \\
\hline $\begin{array}{l}\text { Echevarría } \\
\text { GME, et al } \\
(2018)\end{array}$ & Brasil & $\begin{array}{l}\text { Inglês, } \\
\text { Português }\end{array}$ & $\begin{array}{l}\text { Estudo } \quad \text { quantitativo } \\
\text { longitudinal }\end{array}$ & $\begin{array}{l}2005 \text { a março de } \\
2009 .\end{array}$ & $\begin{array}{l}\text { Pacientes adultos internados em uma unidade de } \\
\text { queimados }\end{array}$ \\
\hline $\begin{array}{l}\text { Moulin LL, et al } \\
(2018)\end{array}$ & Brasil & Português & $\begin{array}{l}\text { Estudo } \quad \text { descritivo, } \\
\text { quantitativo }\end{array}$ & $\begin{array}{l}\text { Janeiro a Junho de } \\
2016 .\end{array}$ & $\begin{array}{l}\text { Pacientes vítimas de queimaduras atendidas em um } \\
\text { Hospital de referência. }\end{array}$ \\
\hline $\begin{array}{l}\text { Martins JT, et al } \\
\text { ( 2014) }\end{array}$ & Brasil & $\begin{array}{l}\text { Espanhol, } \\
\text { Português }\end{array}$ & Estudo Qualitativo & $\begin{array}{l}\text { Julho a setembro de } \\
2012 \text {. }\end{array}$ & $\begin{array}{l}\text { Profissionais de enfermagem assistindo pacientes } \\
\text { com queimaduras }\end{array}$ \\
\hline $\begin{array}{lr}\text { Melo, } & \text { TO } \text { e } \\
\text { Lima, } & \text { AFC } \\
(2017) & \end{array}$ & Brasil & $\begin{array}{l}\text { Espanhol, } \\
\text { Português }\end{array}$ & $\begin{array}{l}\text { Estudo quantitativo, } \\
\text { exploratório e descritivo }\end{array}$ & $\begin{array}{l}\text { Entre janeiro e } \\
\text { fevereiro de } 2015 .\end{array}$ & $\begin{array}{l}\text { Profissionais de enfermagem assistindo pacientes } \\
\text { com queimaduras }\end{array}$ \\
\hline $\begin{array}{l}\text { Padua GAC, et } \\
\text { al (2017) }\end{array}$ & Brasil & $\begin{array}{l}\text { Inglês } \\
\text { Português }\end{array}$ & Estudo Transversal & $\begin{array}{l}2010 \text { a março de } \\
2015 .\end{array}$ & $\begin{array}{l}\text { Pacientes vítimas de queimaduras internados no } \\
\text { Serviço de Cirurgia Plástica e Queimados da Santa } \\
\text { Casa de Misericórdia de Santos }\end{array}$ \\
\hline $\begin{array}{l}\text { Camuci MB, et } \\
\text { al (2014) }\end{array}$ & Brasil & $\begin{array}{l}\text { Inglês, } \\
\text { Espanhol, } \\
\text { Português }\end{array}$ & $\begin{array}{l}\text { Estudo quantitativo, } \\
\text { exploratório- descritiva }\end{array}$ & maio a julho de 1999 & $\begin{array}{l}\text { Profissionais de enfermagem assistindo pacientes em } \\
\text { uma Unidade de Terapia Intensiva de } \\
\text { Queimados }\end{array}$ \\
\hline $\begin{array}{l}\text { Dalmedico MM, } \\
\text { et al } \\
(2016)\end{array}$ & Brasil & $\begin{array}{l}\text { Inglês, } \\
\text { Espanhol, } \\
\text { Português }\end{array}$ & $\begin{array}{l}\text { Estudo descritivo de } \\
\text { ensaios clínicos } \\
\text { randomizados }\end{array}$ & Não informado. & $\begin{array}{l}\text { Pacientes queimados sobre tratamento com ácido } \\
\text { hialurônico }\end{array}$ \\
\hline $\begin{array}{l}\text { Metsavaht Ld'O } \\
(2017)\end{array}$ & Brasil & $\begin{array}{l}\text { Inglês, } \\
\text { Português }\end{array}$ & Estudo retrospectivo & Não informado. & Pacientes queimados \\
\hline $\begin{array}{l}\text { Costa EF, et al } \\
(2017)\end{array}$ & Brasil & Português & Estudo qualitativo & $\begin{array}{l}\text { Dezembro de } 2010 \text { a } \\
\text { janeiro de } 2011\end{array}$ & Pacientes queimados \\
\hline
\end{tabular}

Fonte: Nascimento DKL, et al., 2018.

REAEnf/EJNC | Vol. 1 | e2122 | DOI: https://doi.org/10.25248/REAenf.e2122.2019 Página 7 de 9 
Para possibilitar o cuidado e tratamento de pessoas que sofreram queimaduras de causas variadas, com diversidades de localizações, extensões e profundidades das lesões, é necessário uma equipe multiprofissional e local adequado como nos casos dos Centros de Tratamentos de Queimados, que, geralmente, comportam também Unidades de Terapia Intensiva (UTI) de Queimados (CAMUCI MB, et al., 2014).

A provisão de pessoal de enfermagem necessária ao padrão de atendimento desejado contribui de forma direta para o cuidado com qualidade aos pacientes, garantindo assim, à diminuição da sobrecarga de trabalho que pode estar presente no labor, tornando-o menos degradativo e mais seguro para profissionais, instituição e pacientes (CAMUCI MB, et al., 2014).

No que tange as ações de enfermagem no atendimento aos traumas por queimaduras, estão centradas no Contexto Assistencial e Educativo e relacionam-se as necessidades psicobiológicas, psicossociais e psicoespirituais: oxigenação, hidratação e nutrição, eliminação, sono e repouso, higiene corporal e oral, integridade cutâneo-mucosa e física, mobilidade/locomoção, regulação, percepção dolorosa, terapêutica, comunicação e aprendizagem, gregária, religiosa e ética. Em referência a parte Gerencial, apontam-se aspectos da gestão: fornecimento de estrutura e ambiente, isolamento, escala de enfermagem, equipe de enfermagem e multiprofissional (PINHO FM, et al., 2016).

No segundo momento, as ações devem ser direcionadas a fase da queimadura, sejam na Fase Imediata: medidas necessárias que ocorrem entre as horas iniciais da queimadura até o primeiro desbridamento da pele; na Fase Intermediária: medidas de tratamento entre o primeiro desbridamento até a enxertia da pele; e na Fase Tardia: medidas de tratamento entre a enxertia até a regeneração total da pele (PINHO FM, et al., 2016)..

Em relação a ferida, o tratamento objetiva primordialmente acelerar a cicatrização e conter a deposição abundante de colágeno nas cicatrizes para prevenção da ocorrência de queloides e contraturas. 0 tratamento tópico aconselhado a uma lesão por queimadura observa a utilização de produtos que controlem a proliferação e colonização bacteriana, eliminem o tecido não-sadio, considerado desvitalizado e favoreçam a transição entre o tecido sadio, de granulação ou revitalização até a total epitelização tecidual, ou seja, a cicatrização (DALMEDICO MM, et al., 2016).

A identificação de coberturas é determinada nos efeitos sobre a cura, na simplicidade de aplicação e retirada do produto, no custo de tratamento e conforto para o paciente. A terapia com maior êxito pode direcionar à recuperação da função fisiológica, ao alívio ou diminuição dos sintomas, como a dor ou prurido, sensibilidade alterada, e à restauração estética e funcional das lesões sem a ocorrência de cicatrizes hipertróficas ou queloides (DALMEDICO MM, et al., 2016).

A emergência e o prognóstico de uma queimadura, além da necessidade ou não da internação hospitalar, são determinados após a avaliação do agente causal, profundidade, extensão da superfície corporal queimada, localização, idade, doenças preexistentes e lesões associadas. A nomenclatura tradicional classifica as feridas por queimadura em primeiro, segundo e terceiro graus. Em segundo grau, observa-se a subdivisão em variantes superficial e profunda. As queimaduras profundas como as que atingem músculos e ossos podem ser incluídas como as de quarto grau. No entanto, o diagnóstico final da profundidade de uma queimadura só é determinado após período que varia de 24 a 72 horas, por causa das alterações vasculares oclusivas (METSAVAHT Ld'O, 2017).

Num contexto geral, o trauma por queimadura é uma das mais traumáticas e dolorosas experiências vivenciadas que uma pessoa possa ter. Apontada, geralmente, como um acontecimento inesperado que pode modificar relativamente o cotidiano, no qual, o indivíduo ativo passa a ser impossibilitado de continuar suas atividades nas esferas biopsicossocial e ocupacional. Em situações mais isoladas, o corpo pode ficar desfigurado, sem partes do tecido tegumentar. Em diversos casos são necessários intervenções cirúrgicas, como a enxertia, que é consiste num processo doloroso e que pode danificar ainda mais o corpo, além haver a possibilidade de sequelas e a dúvida quanto a volta ao pleno desempenho ocupacional (COSTA EF, et al., 2017). 


\section{CONSIDERAÇÕES FINAIS}

Através da análise dos artigos foi possível identificar e descrever a assistência de enfermagem prestada ao paciente vítima de trauma por queimadura. As manifestações clínicas e as principais consequências do trauma por queimadura, caracterizam um grau de dependência da equipe multiprofissional de assistência a este tipo de paciente. Diante disso, o desenvolvimento e aperfeiçoamento da assistência de enfermagem devem ser de modo planejado e dinâmico que possibilite identificar, compreender, descrever, explicar e predizer quais as necessidades do paciente, família e coletividade humana em determinado momento do processo saúde e doença. De modo dinâmico, a equipe de enfermagem tem um papel importante nesse tipo de assistência, pois, atuam diretamente no atendimento inicial, nos casos de urgência e/ou emergência, até a total ou parcial recuperação da área afetada, diminuindo os riscos provenientes ao paciente. Além disso, elabora planos contínuo de cuidados para o tratamento e, assim, garantindo, após a alta hospitalar, a manutenção de habilidades, capacidades funcionais e psicoemocionais para o desempenho de atividades diárias, permitindo ao paciente, que mantenha a autonomia, a independência, o bem-estar e a qualidade de vida.

\section{REFERÊNCIAS}

1. SILVA LD, et al. Assistência de enfermagem ao paciente grande queimado submetido à sedação e analgesia: uma revisão de literatura. Nursing (São Paulo), 2018; 21(236): 2021-2026.

2. QUEIROZ RCPF de, et al. Perfil dos pacientes evasores atendidos no ambulatório de queimados do Conjunto Hospitalar de Sorocaba. Revista brasileira de Queimaduras, 2015; 14(4): 263-267.

3. SILVA JB, et al. Atendimento inicial às queimaduras de mão: revisão da literatura. LILACS / Portal Regional da BVS, 2015; 25(2): ID20908.

4. JÚNIOR JLR, et al. Terapia ocupacional em queimados: pesquisa bibliográfica acerca da reabilitação física junto a indivíduos com queimaduras. Revista brasileira de Queimaduras, 2014; 13(1): 11-17.

5. SILVA RV, et al. Fatores de risco e métodos de prevenção de queimaduras em idosos. Revista Brasileira Cirurgia Plástica, 2015; 30(3): 461-467.

6. GONELLA HÁ, et al. Colonização bacteriana nas primeiras 24 horas das queimaduras. Revista brasileira de Queimaduras, 2014; 13(2): 99-102.

7. BISCEGLI TS, et al. Perfil de crianças e adolescentes internados em Unidade de Tratamento de Queimados do interior do estado de São Paulo. Revista Paulista de Pediatria, 2014; 32( 3 ): 177-182.

8. LIMA GM de, et al. Características dos pacientes que apresentaram queimadura de face em hospital de referência na região amazônica. Revista brasileira de Queimaduras, 2015;14(2): 133-139.

9. MORAES PS de, et al. Perfil das internações de crianças em um centro de tratamento para queimados. Revista eletrônica enfermagem, 2014; 16(3): 598-603.

10. PINHO FM de, et al. Guideline das ações no cuidado de enfermagem ao paciente adulto queimado. Revista brasileira de Queimaduras, 2016; 15(1): 13-23.

11. SILVA JAC da, et al. Epidemiologia, principais complicações e mortalidade dos pacientes atendidos em um Centro de Tratamento de Queimados na Amazônia. Revista Brasileira Cirurgia Plástica, 2018; 33(1): 104-109

12. ECHEVARRÍA GME, et al. Avaliação da qualidade de vida relacionada à saúde no primeiro ano após a queimadura. Escola Anna Nery, 2016; 20( 1 ): 155-166.

13. MOULIN LL, et al. Perfil sociodemográfico e clínico de vítimas de queimaduras atendidas em um hospital de referência. Nursing (São Paulo),2018; 21(238): 2058-2062.

14. MARTINS JT, et al. Sentimentos vivenciados pela equipe de enfermagem de um centro de tratamento de queimados. Escola Anna Nery, 2014; 18 ( 3 ): 522-526.

15. MELO TO, LIMA AFC. Cost of nursing most frequent procedures performed on severely burned patients. Revista Brasileira Enfermagem, 2017; 70( 3 ): 481-488.

16. PADUA GAC, et al. Epidemiologia dos pacientes vítimas de queimaduras internados no Serviço de Cirurgia Plástica e Queimados da Santa Casa de Misericórdia de Santos. Revista Brasileira Cirurgia Plástica,2017;32(4):550-555.

17. CAMUCI MB, et al. Nursing Activities Score: nursing work load in a burns Intensive Care Unit. Rev. Latino-Am. Enfermagem, $2014 ; 22(2)$ : 325-331.

18. DALMEDICO MM, et al. Coberturas de ácido hialurônico no tratamento de queimaduras: revisão sistemática. Revista Escola enfermagem USP, 2016; 50( 3 ): 522-528.

19. METSAVAHT Ld'O. Queimaduras e suas cicatrizes. Surg. cosmet. Dermatol, 2017;9(4): 281-284.

20. COSTA EF, et al. Sobre a forma ocupacional após acidente por queimaduras. Cad. Bras. Ter. Ocup,207; 25(3): [543-551]. 